\title{
Stocking density effects on growth and production of the threatened silurid catfish, Mystus cavasius (Hamilton) fingerlings in nursery ponds
}

\begin{abstract}
The fingerling-rearing experiment of the threatened catfish, Mystus cavasius was carried out at different stocking densities in earthen nursery ponds. Twelve-day-old fry were stocked at 200000 ha-1 in treatment-1 (T1), 250000 ha-1 in treatment-2 (T2) and 300000 ha-1 in treatment-3 (T3) respectively. The mean length and weight of fry at stocking was $1.24 \pm 0.25$ $\mathrm{cm}$ and $0.11 \pm 0.04 \mathrm{~g}$ respectively. Fry in all the experimental ponds were supplemented with SABINCO nursery feed for the first 14 days and starter-I feed for days $15-56$. The physicochemical parameters and plankton population of pond water were within the suitable level for fish culture. Growth in terms of final weight, final length, weight gain, length gain and specific growth rate and survival of fingerlings were significantly higher in T1 than those in $\mathrm{T} 2$ and T3. Feed conversion rate was significantly lower in $\mathrm{T} 1$ followed by $\mathrm{T} 2$ and $\mathrm{T} 3$ in that order. Significantly higher number of fingerlings was produced in T3 than that in T2 and T1. Even then, consistently higher net benefits were obtained from T1 than those from T3 and T2. Among the treatments evaluated, 200000 fry ha -1 was the best stocking density considering the highest growth, production and net benefits of fingerlings of M. cavasius in nursery ponds.
\end{abstract}

Keyword: Mystus cavasius; Fry; Stocking density; Fingerling; Production; Benefit 